\title{
A BRIEF REVIEW ON DIFFERENT STEEL MEMBERSUNDER COMBINED AXIAL LOAD AND MOMENTAS PER IS: 8002007
}

\author{
GargiDanda De ${ }^{1}$, Mohan Gupta ${ }^{2}$ \\ ${ }^{1}$ Assistant Professor, BIT, Durg \\ ${ }^{2}$ Professor \& Head Civil Engineering Department, BIT Durg
}

\begin{abstract}
In a compression member when significant bending is present, it's called a beam-column. It is very common that the structural members are subjected to a combination of axial force and bending moment. Example of Compression members subjected to axial load and bending in structure are innumerable. Slender beam-columns are weak in torsion and may be subjected to lateraltorsional buckling. In this paper behavioural studies will be done on rolled and built up members with manual calculations and excel sheet for perfection.
\end{abstract}

Keywords: Beam-Column, Buckling, Radius of Gyration, Rolled Steel

\section{INTRODUCTION}

Beam-column are very common structural members which are referred to a combination of axial force and bending moment. Example of Compression members subjected to axial load and bending in structure are steel mast, towers, etc. Masts are the tall structures with relatively small crosssection i.e., a large ratio between the height and the maximum width. There are many challenges for the engineers who are associated with the set all and slender structures. The number of collapses of masts is relatively far greater than for other types of structures.

It is normally a steel structure pin connected to its foundation and braced with guys or other elements. A mast is a simple vertical post embedded in the foundation or rigidly fixed in vertical position to support the overhead equipment with can tilever assembly.

\section{DESIGN OF A COMPOUND COLUMN}

A built-up section is a more practical design than using a rolled shape in many situations. This is particularly true when there is a very long unsupported column length involved such that to meet the $\mathrm{L} / \mathrm{r}$ requirements would require one of the heavier rolled sections. Another factor of primary importance is that the radius of gyration of built- up members can be controlled to produce maximum section efficiency. This efficiency cannot be obtained using the standard rolled sections, where the ratio of $r_{x} / r_{y}$ is often 1.5 to 5 or more, unless bracing is provided with respect to the $\mathrm{Y}$ axis.

It is somewhat more difficult to produce an optimum, or least-weight, built-up section since there are several design parameters to satisfy, including:

1. Types of members to use.

2. Arrangement of the basic members, including any size limitations for overall section dimensions.
3. The resulting computed values of $I_{x}, I_{y}, r_{x}$ and $r_{y}$ and $K L$ $/ r_{\max }$, which produce the allowable compression stress.

One or more iterations are usually required to finally develop a satisfactory section. Built-up sections may be built using rolled section, but more commonly are constructed using lacing or batten plates. The design of a built-up member requires at least the following steps:

1. Assumeanallowableaxialcompressivestress(assume110$120 \mathrm{n} / \mathrm{mm}^{\wedge} 2$ )

2. Findoutthegrossarearequired

3. Grossarea $=$ axialloadonthecolumn/assumepermissibleco mpressivestress

4. Tryasection

5. Arrangethecomponentmembersofthesectioninsuchaway, thatthemomentofinertiaofthesectionaboutboththeprincip alaxisisthesame,i.e., $\mathrm{I}_{\mathrm{xx}}=\mathrm{I}_{\mathrm{yy}}$,

6. Findoutthevalueoftheleastradiusofgyrationwhichwillbee qualtor $r_{x x}$

becauseI $_{\mathrm{yy}}$ ismadeequaltoorgreaterthanI $\mathrm{I}_{\mathrm{yy}}$, , othattheradius ofgyrationislargestpossibleinboththedirection.

7. Calculateslendernessratiol $/ \mathrm{r}$, anoteshouldbemadethattheeffectivelengthforbattenedcol umnswillbeincreasedby $10 \%$.

8. Forthecalculatevalueofslendernessratiol/r,findoutthevalu eofallowableaxialcompressivestress $\left(\mathrm{P}_{\mathrm{ac}}\right)$.

9. Nowcalculatethesafeloadfortheassumedsection.

10. Safeload $=\mathrm{P}_{\mathrm{ac}} \mathrm{xareaofthesection.}$

If it is equal to or little more than the axial load, the section is satisfactory, otherwise tried for another section.

Latticing and Battening are the means of connecting the various component members of a compound section and they should be designed that the failure of the composite section may be only due to the direct crushing and not due to buckling. 
The lacing is most commonly used; the rolled steel flats, angles and channels are used for lacing. Battening is another method of connecting the different component members of a built-up section. It is generally not used where the column is subjected to eccentric loading.

Table 1: Design of b-series

\begin{tabular}{|l|l|l|l|}
\hline Batten column & B-175 & B-200 & B-250 \\
\hline $\mathrm{B}(\mathrm{mm})$ & 175 & 200 & 250 \\
\hline Areacm & & 76.34 \\
\hline $\mathrm{Ixx}\left(\mathrm{cm}^{4}\right)$ & 48.76 & 56.42 & 12912.4 \\
\hline $\mathrm{Iyy}\left(\mathrm{cm}^{4}\right)$ & 8230.8 & 9568 & 7633.6 \\
\hline $\mathrm{Zxx}\left(\mathrm{cm}^{3}\right)$ & 2446.6 & 3638.6 & 860.8 \\
\hline $\mathrm{Zyy}\left(\mathrm{cm}^{3}\right)$ & 548.7 & 637.9 & 611 \\
\hline $\mathrm{Yyy}\left(\mathrm{cm}^{2}\right.$ & 280 & 364 & 9.94 \\
\hline$\sigma_{\mathrm{ac}}\left(\mathrm{N} / \mathrm{mm}^{2}\right)$ & 7.08 & 8.03 & 99 \\
\hline$\sigma_{\mathrm{bcx}}\left(\mathrm{N} / \mathrm{mm}^{2}\right)$ & 68 & 78.8 & 112.3 \\
\hline$\sigma_{\mathrm{bcy}}\left(\mathrm{N} / \mathrm{mm}^{2}\right)$ & 82 & 93.7 & 165 \\
\hline
\end{tabular}

Table 2: Design of 254 series of UC section

\begin{tabular}{|c|c|c|c|c|c|}
\hline Section & $254 \times 254 \times 167$ & $254 \times 254 \times 132$ & $254 \times 254 \times 107$ & $254 \times 254 \times 89$ & $254 \times 254 \times 73$ \\
\hline mass & 167.1 & 132 & 107.1 & 88.9 & 73.1 \\
\hline depth & 289.1 & 276.3 & 266.7 & 260.3 & 254.1 \\
\hline width & 265.2 & 261.3 & 258.8 & 256.3 & 254.6 \\
\hline web th & 19.2 & 15.3 & 12.8 & 10.3 & 8.6 \\
\hline flange th & 31.7 & 25.3 & 20.5 & 17.3 & 14.2 \\
\hline root rad & 12.7 & 12.7 & 12.7 & 12.7 & 12.7 \\
\hline $\mathrm{b} / \mathrm{T}$ & 4.18 & 5.16 & 6.31 & 7.41 & 8.96 \\
\hline $\mathrm{d} / \mathrm{t}$ & 10.4 & 13.1 & 15.6 & 19.4 & 23.3 \\
\hline ixx & 30000 & 22500 & 17500 & 14300 & 11400 \\
\hline iyy & 9870 & 7530 & 5930 & 4860 & 3910 \\
\hline $\operatorname{rxx}$ & 11.9 & 11.6 & 11.3 & 11.2 & 11.1 \\
\hline ryy & 6.81 & 6.69 & 6.59 & 6.55 & 6.48 \\
\hline exx & 2080 & 1630 & 1310 & 1100 & 898 \\
\hline eyy & 744 & 576 & 458 & 379 & 307 \\
\hline $\mathrm{zxx}$ & 2420 & 1870 & 1480 & 1220 & 992 \\
\hline zyy & 1140 & 878 & 697 & 575 & 465 \\
\hline $\mathrm{D} / \mathrm{T}$ & 9.119874 & 10.92095 & 13.0097561 & 15.0462428 & 17.8943662 \\
\hline slratioxx & 101.7254 & 103.5501 & 105.1213961 & 105.763359 & 106.9058642 \\
\hline area & 213 & 168 & 136 & 113 & 93.1 \\
\hline sl ratio & 119.6769 & 121.8236 & 123.6722307 & 124.427481 & 125.7716049 \\
\hline fcc & 137.6792 & 132.8698 & 128.9273047 & 127.366928 & 124.6591284 \\
\hline sig ac & 63.8616 & 62.28584 & 60.96394719 & 60.4331181 & 59.50150571 \\
\hline sig bcx & 1899.24 & 1858.542 & 1885.674 & 1722.882 & 1668.618 \\
\hline sig bcy & 2238.39 & 2238.39 & 2238.39 & 2238.39 & 2238.39 \\
\hline ev & 1907.45 & 1574 & 1337.45 & 1164.55 & 1014.45 \\
\hline ac stress & 8.955164 & 9.369048 & 9.834191176 & 10.3057522 & 10.89634801 \\
\hline ac ben comx & 110.9091 & 143.5294 & 181.3513514 & 220 & 270.5645161 \\
\hline abencoyy & 10 & 12.98405 & 16.35581062 & 19.826087 & 24.51612903 \\
\hline Safe $<1$ & 0.073201 & 0.094116 & 0.115371052 & 0.14912082 & 0.186600426 \\
\hline
\end{tabular}




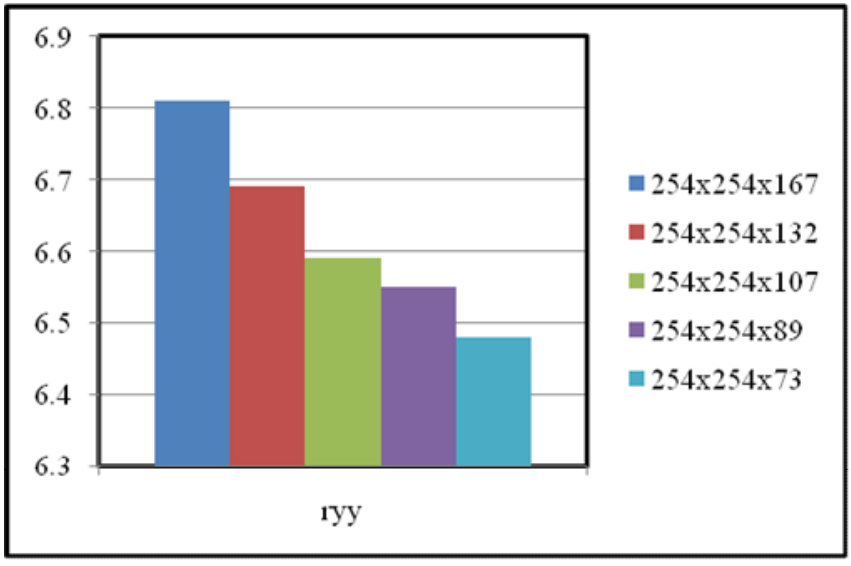

Fig. 1: Radius of gyration of 254 series of UC section

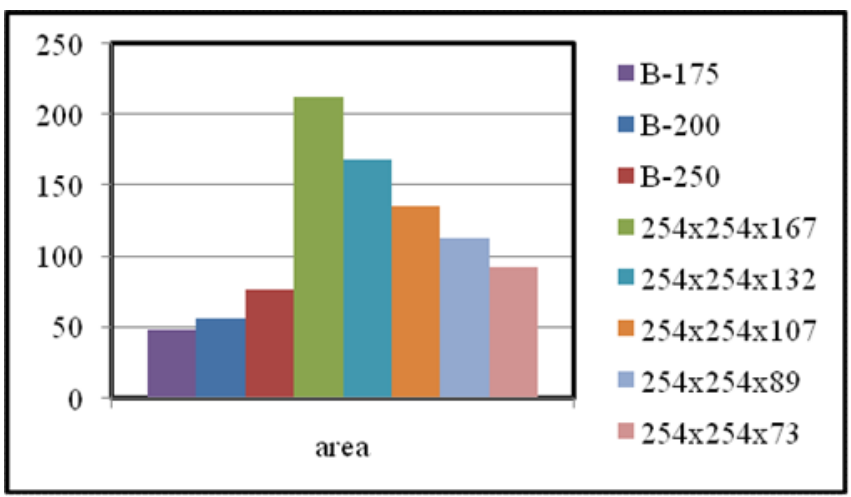

Fig. 2: Area of UC and B-series section

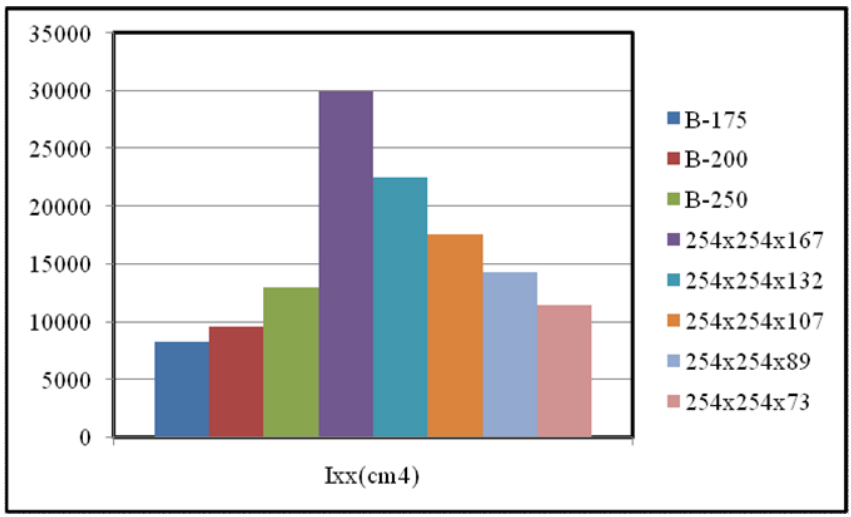

Fig. 3: Moment of inertia of UC \& B-series

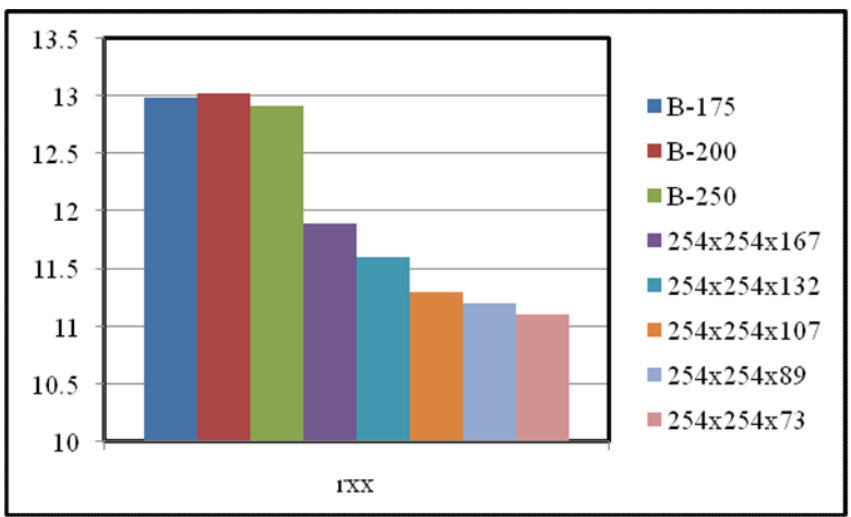

Fig. 4: Radius of gyration of UC \& B-series

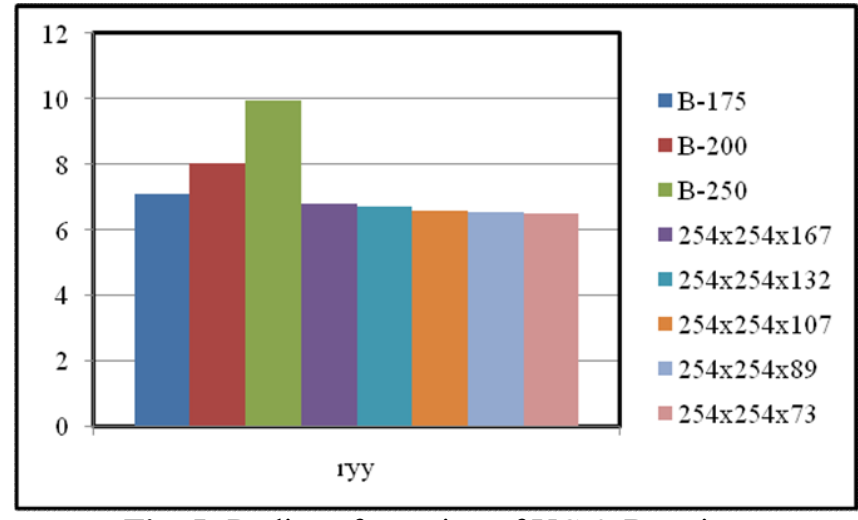

Fig. 5: Radius of gyration of UC \& B-series

Here in this bar chart radius of gyration about y-axis compared with B-series and UC 254 series of section. It shows that 254 series is not suitable in replace of B-series. By increasing the section here 305 series of UC section can be try.

From design point of view $305 \times 305 \times 97$ section is the save one. Then by comparing with existing B-series mast

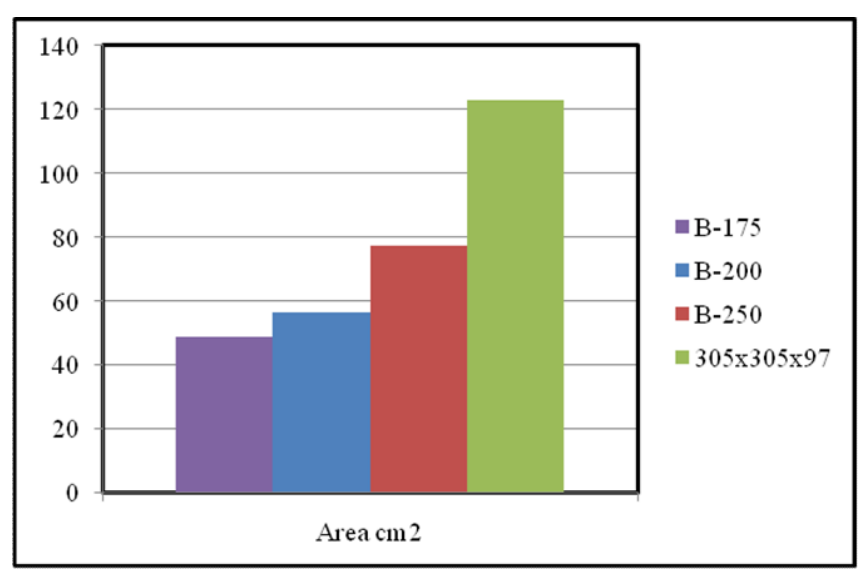

Fig. 6: Area of 305x305x97 \& B-series

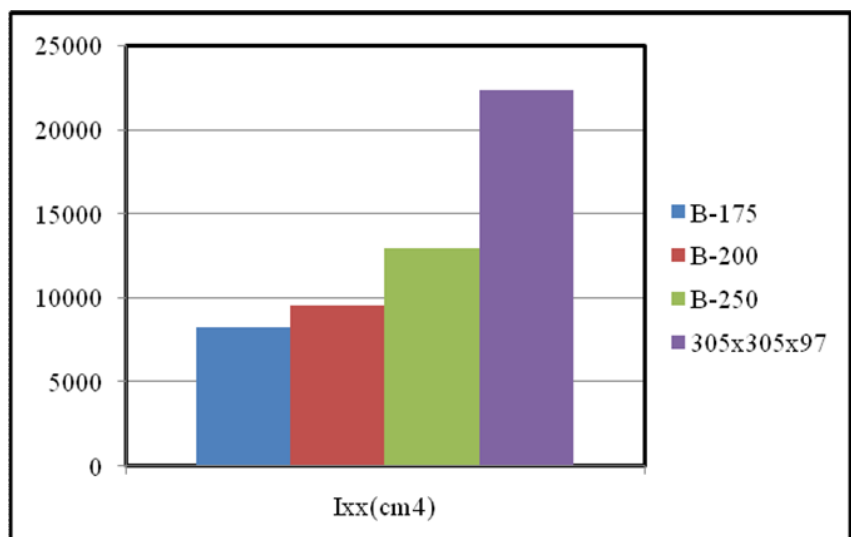

Fig. 7: Moment of inertia of $305 \times 305 \times 97$ \& B-series

Here from this bar chart $305 \times 305 \times 97$ UC section is compared with B-series, it is noted that moment of inertia about $\mathrm{X}$-axis is much higher than B-series. 


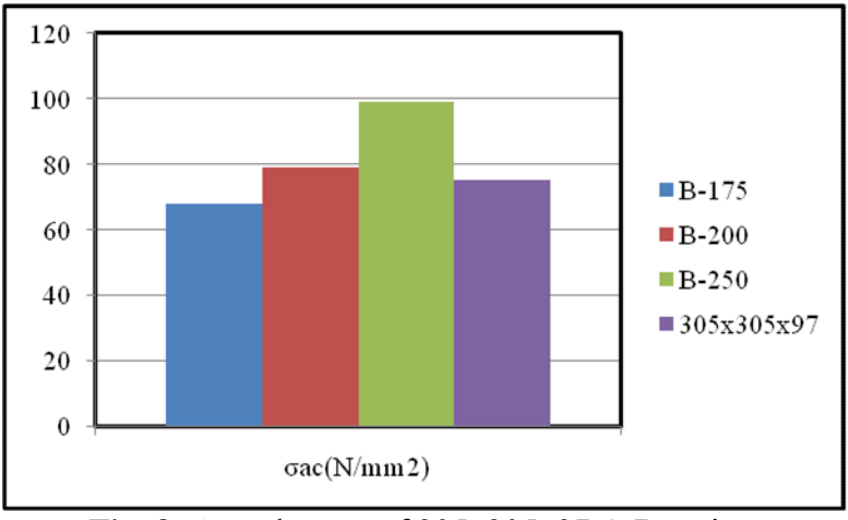

Fig. 8: Actual stress of $305 \times 305 \times 97 \&$ B-series

Actual stress of the UC section is higher than B-175, but with compare with B-200, it is slightly less. The actual stress of B-250 is much higher here.

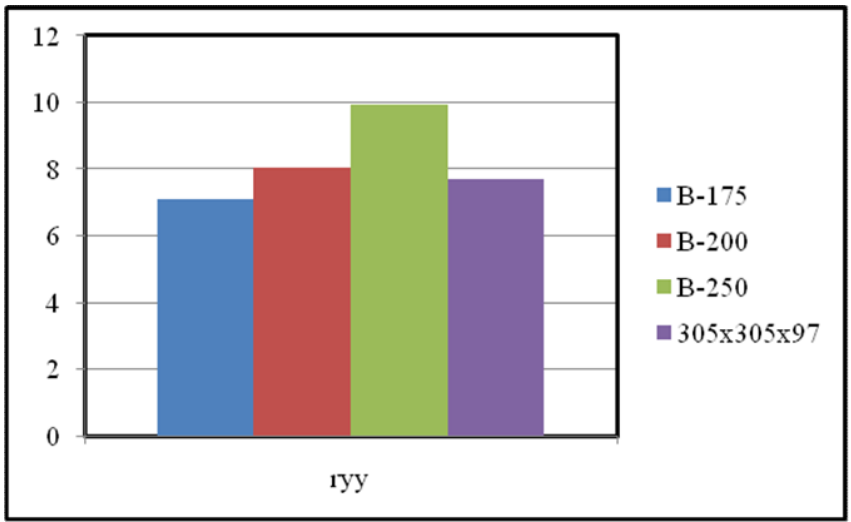

Fig. 9: Radius of gyration of $305 \times 305 \times 97$ \& B-series

The radius of gyration of this new section is approximately same as B-200, and better than B-175.

Table 3: Radius of gyration of $305 \times 305 \times 97$ \& B-series

\begin{tabular}{|l|l|l|l|l|}
\hline $\begin{array}{l}\text { Mast } \\
\text { type }\end{array}$ & B-175 & B-200 & B-250 & $\mathbf{3 0 5 x 3 0 5 x 9 7}$ \\
\hline$r_{x x}$ & 12.99239381 & 13.02249 & 12.92116 & 13.4 \\
\hline$r_{y y}$ & 7.083528364 & 8.030648 & 9.93488 & 7.69 \\
\hline
\end{tabular}

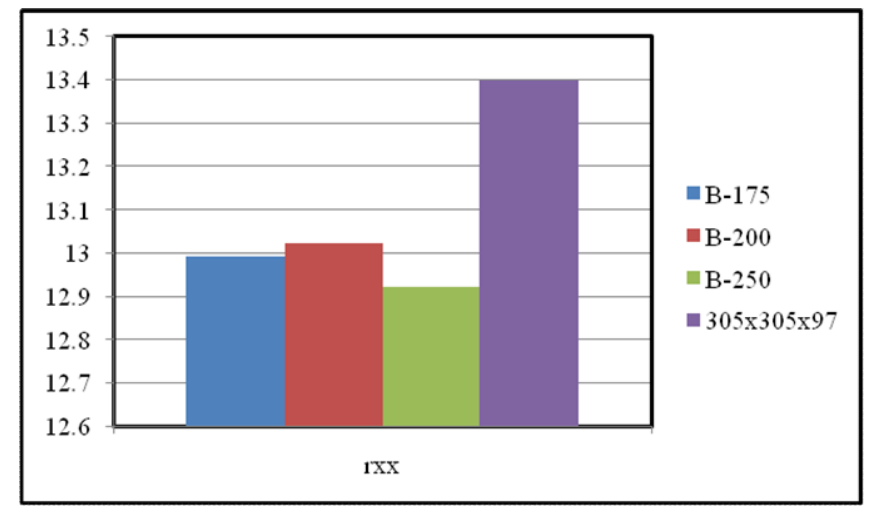

Fig. 10: Radius of gyration of $305 \times 305 \times 97$ \& B-series

The radius of gyration of $\mathrm{UC}$ section about $\mathrm{x}$-axis is much higher than $\mathrm{B}$ series.
From these bar graph this will be satisfy that $305 \times 305 \times 97$ UC section can be use instead of B9.9-175 \& B-200 mast.

\section{CONCLUSION}

- For replacement of built up section, higher sections are tried, which have safe design. On these sections $305 \times 305 \times 93$ have theoretically better onthe performance of radius of gyration, and on various stresses.

- So, in place of B-175 and B-200 which are used as an anchored mast and the mast carry balanced weight, may be tried with $305 \times 305 \times 93$.

- All these are theoretical calculations according to IS 800:2007 code. So laboratory test will be required for implementation.

- Here it is clear that built up section is always preferable for higher load cases and on different load combination.

\section{REFERENCES}

[1] UlrikStottup-Andersen, "Masts and towers", Euro steel 2005, Maastricht Nederland, June 2005.

[2] Steel columns of rolled wide flange section, progress report no.1, by Bruce Johnston and Lloyd Cheney, American Institute of Steel construction column research at Lehigh University. Committee of technical research, AISC.

[3] Indian standard IS 800 - 1984 code of practice for general construction in steel, first revision, copyright 1995, Bureau of Indian standards.

[4] Indian standard IS 875 codes of practices.

[5] Indian standard IS 800 - 2007 code of practices.

[6] Indian standard IS 808:1989 - 2004 Hot rolled steel sections, edition 4.1 .

[7] Indian standard IS 1852:1985 - 2003 code of practices.

[8] Overhead equipment mast - Indian Railways Institute of Electrical Engineering, Nasik Road.

[9] H. Partab, Modern Electric traction, edition 1989, Dhanpat Rai and sons.

[10] Joseph E. Bowles, Structural Steel Design, copyright 1981, McGrawhill Book Company.

[11] Buick Davison and Graham W. Owens, Steel Designers' manual, Blackwell Publishing, 6th edition.

[12] N. Subramanian, Design of Steel Structures, Oxford University press 2008.

[13] Bhagwan Das Ahirwar - Reliability of 25 KV traction, IREEN journal, vol.13, no.4, oct-Dec 2003.

[14] Om Prakash -“Optimisation of cost of electrification", IRIEEN journal, vol.III, Oct-Dec 1993, No.4.

[15] R.K Saxena - "Enhancement of speed potential of OHE”, IRIEEN Journal, vol.IX, Oct-Dec 1999, No.4. 